\title{
Shared and Unique Features of Evolutionary Diversification
}

\author{
R. Brian Langerhans ${ }^{\star}$ and Thomas J. DeWitt ${ }^{\dagger}$
}

Department of Wildlife and Fisheries Sciences, Texas A\&M University, 2258 TAMU, College Station, Texas 77843-2258

Submitted August 8, 2003; Accepted April 15, 2004;

Electronically published August 12, 2004

ABSTRACT: A fundamental question in evolutionary biology asks whether organisms experiencing similar selective pressures will evolve similar solutions or whether historical contingencies dominate the evolutionary process and yield disparate evolutionary outcomes. It is perhaps most likely that both shared selective forces as well as unique histories play key roles in the course of evolution. Consequently, when multiple species face a common environmental gradient, their patterns of divergence might exhibit both shared and unique elements. Here we describe a general framework for investigating and evaluating the relative importance of these contrasting features of diversification. We examined morphological diversification in three species of livebearing fishes across a predation gradient. All species (Gambusia affinis from the United States of America, Brachyrhaphis rhabdophora from Costa Rica, and Poecilia reticulata from Trinidad) exhibited more elongate bodies, a larger caudal peduncle, and a relatively lower position of the eye in predator populations. This shared response suggests that common selective pressures generated parallel outcomes within three different species. However, each species also exhibited unique features of divergence, which might reflect phylogenetic tendencies, chance events, or localized environmental differences. In this system, we found that shared aspects of divergence were of larger magnitude than unique elements, suggesting common natural selective forces have played a greater role than unique histories in producing the observed patterns of morphological diversification. Assessing the nature and relative importance of shared and unique responses should aid in elucidating the relative generality or peculiarity in evolutionary divergence.

Keywords: convergent evolution, divergent natural selection, ecomorphology, historical contingency, geometric morphometrics, population differentiation.

\footnotetext{
* Corresponding author. Present address: Department of Biology, Campus Box 1137, Washington University, St. Louis, Missouri 63130-4899; e-mail: langerhans@wustl.edu.

† E-mail: tdewitt@tamu.edu.
}

Am. Nat. 2004. Vol. 164, pp. 335-349. (C) 2004 by The University of Chicago. 0003-0147/2004/16403-40054\$15.00. All rights reserved.
Two contrasting views exist in evolutionary biology concerning the dominant forces driving diversification. On one hand, unique histories among organisms might play a major role in evolutionary outcomes, thus producing disparate results under similar selection (i.e., historical contingency; Pianka 1986; Gould 1989; Gould and Woodruff 1990; Cadle and Greene 1993; Price et al. 2000). Such differences in evolutionary outcomes presumably derive from clade-specific factors as well as chance historical happenings and localized environmental differences (Harvey and Pagel 1991). In contrast, natural selection might play a dominant role in evolutionary diversification, thus producing similar outcomes under similar environmental circumstances (Schluter 1996b, 2000; Losos et al. 1998). According to this view, natural selection could overwhelm the vagaries of history and produce evolutionary convergence. Probably more likely is that both unique histories as well as common natural selective forces play key roles in the evolutionary process (Winemiller 1992; Travisano et al. 1995; Huey et al. 2000; Schluter 2000; Taylor and McPhail 2000; Hendry and Kinnison 2001; Johnson 2002; Matos et al. 2002; Ruzzante et al. 2003). Thus, when multiple groups of organisms face a common environmental gradient, their patterns of divergence might exhibit both shared and unique elements.

Many groups of organisms experience similar environmental gradients. For instance, diversification has presumably occurred multiple times across light-availability regimes in plants (Smith and Whitelam 1997; Ballaré 1999; Donohue et al. 2000; Weinig 2000; Monaco and Briske 2001; Pigliucci et al. 2003), across benthic and limnetic habitats in fishes (Robinson and Wilson 1994; Schluter 1996c; Smith and Skúlason 1996), and across predator regimes in larval anurans (Lardner 2000; Relyea 2001; Richardson 2001; Van Buskirk 2002). Despite the potential ubiquity of convergent/divergent patterns of diversification, no general framework has been established to investigate these two contrasting patterns of evolutionary outcomes. Here we describe a framework that simultaneously quantifies both shared and unique responses to a common environmental gradient among multiple groups of organisms. 
Table 1: General analytical framework

\begin{tabular}{|c|c|c|c|c|c|c|}
\hline $\begin{array}{c}\text { Phenotype(s) } \\
\text { (Example: morphology, life } \\
\text { history, behavior) }\end{array}$ & $=$ & $\begin{array}{l}\text { Enviromental gradient } \\
\text { Shared responses } \\
\text { (Example: predator regime, } \\
\text { habitat type, climate) }\end{array}$ & + & $\begin{array}{c}\text { Unique histories } \\
\text { Specific history effect } \\
\text { (Example: species, geographic } \\
\text { region, genotype, clade) }\end{array}$ & + & $\begin{array}{c}\text { Gradient } \times \text { History } \\
\text { Unique response } \\
\text { (Example: effect of habitat on } \\
\text { phenotype depends on species) }\end{array}$ \\
\hline
\end{tabular}

\section{General Framework}

Typically, studies in this field follow one of two paths. One is to conduct separate analyses for each group of organisms (often in separate studies), qualitatively compare results to evaluate convergence in patterns, and briefly explore unique responses (Endler 1982; Peer et al. 1999; Lardner 2000; Relyea 2001; Jennions and Telford 2002; Johannesson 2003; Langerhans et al. 2003; McGuigan et al. 2003). The second path is to explicitly test and quantify convergence but essentially ignore potential unique aspects of evolutionary results (Losos 1992; Schluter and McPhail 1992; McPeek 1995; Losos et al. 1998). To better understand mechanisms of diversification, shared and unique features of evolutionary divergence should be quantified simultaneously in equivalent units. This can be done in one analysis by examining aspects of phenotypic variation associated with the common environmental gradient, unique historical factors, and unique responses to the gradient. This approach allows for comparisons of the nature and relative magnitudes of each of these factors within a single trait space. The general framework is shown in table 1.

Under this framework, researchers measure relevant characters of organisms across a predetermined environmental gradient and perform statistical analyses analogous to the general formula above. For example, one could investigate shared and unique responses in aspects of leaf shape (phenotype) across light-availability regimes (environmental gradient) among multiple plant species (unique histories) by performing a multivariate analysis of variance (MANOVA). Canonical axes representing linear combinations of the response variables (i.e., aspects of leaf shape) are generated for each term (i.e., gradient, history, interaction) in the model. These canonical axes describe the following: divergence in leaf shape between light regimes that are shared by each species (shared response), species differences in leaf shape (specific history effect), and leaf shape divergence across the gradient that differs among species (unique response). Shared and unique responses can then be quantified and evaluated within one (multidimensional) trait space (fig. 1). The relative importance of each factor can be assessed by comparing the significance and magnitude of effect for each independent variable. Shared responses are expected to be of great importance when common selective forces have produced convergent patterns. The effect of unique histories is expected to be high when comparing distantly related groups or when large environmental differences exist among the groups of organisms. Unique responses are expected to largely arise from unique histories and thus will often be most important in systems with more distinct histories.

\section{Study System}

In order to examine shared and unique features of diversification, we would ideally start with similar organisms and present these organisms with an evolutionary problem: two alternative environments that exhibit large differences in selective pressures. We would then allow sufficient time for evolutionary divergence and return to examine for all groups the shared and unique aspects of evolution under the common environmental gradient. Fortunately, an analogous natural experiment has already occurred in the New World livebearing fishes of the family Poeciliidae. Many poeciliid fishes inhabit environments that differ markedly in predator regime: some environments contain piscivorous fishes while other environments are largely devoid of such fishes. Thus, livebearing fishes may represent a model system for the investigation of convergent and divergent patterns of diversification between predatory environments.

Poeciliid fishes are small bodied, mature rapidly, and inhabit a wide variety of environments throughout North, Central, and South America, as well as the islands of the Caribbean. Many researchers have investigated phenotypic diversification in poeciliid fishes across environments differing in the presence of piscivorous fishes. Livebearing fishes have proven to be ideal models for evolutionary studies, and predator-driven diversification is well documented for some poeciliids (Meffe and Snelson 1989b; Endler 1995; Reznick 1996; Houde 1997; Reznick et al. 1997; Johnson and Belk 2001; Jennions and Telford 2002). Differences in life-history characteristics and demography in relation to predation from piscivorous fishes have been especially well described for several species in this family (Krumholz 1963; Sohn 1977; Reznick 1989; Rodd and Reznick 1997; Downhower et al. 2000; Johnson and Belk 2001; Jennions and Telford 2002). Behavioral and body color divergence between 
predatory environments has also been extensively studied for Trinidadian guppies (Poecilia reticulata; Seghers 1973; Endler 1978, 1980, 1983, 1995; Breden and Stoner 1987; Breden et al. 1987; Winemiller et al. 1990; Magurran et al. 1992, 1995; Houde 1997). These differences reflect fitness trade-offs between high- and low-predation environments.

For this study, we evaluated morphological diversification among predatory environments for three different species (Gambusia affinis, Brachyrhaphis rhabdophora, Poecilia reticulata), each native to a different geographic region. Across the southeast United States, populations of western mosquitofish (G. affinis) are found in habitats ranging from drainage ditches to lakes and rivers, all of which have widely varying suites of aquatic predators (Meffe and Snelson 1989a). Throughout northwestern Costa Rica, B. rhabdophora is widely distributed among a variety of freshwater stream habitats that vary greatly in fish community structure, particularly the presence of piscivorous fishes (Bussing 1998). Poecilia reticulata represents a different tribe of the family Poeciliidae (Poeciliini vs. Gambusiini; Rosen and Bailey 1963; Parenti and Rauchenberger 1989; Ghedotti 2000) and inhabits a large range of habitats varying in predator regime in northeastern Venezuela and adjacent islands (Rosen and Bailey 1963; Seghers 1974; Endler 1978).

Multiple selective pressures might differ between predatory environments causing divergent body morphologies. One major difference might involve selection for body shapes that increase fast-start escape speed to avoid predation in the presence of piscivorous fishes (Howland 1974; Webb 1982, 1986; Weihs and Webb 1983; Harper and Blake 1990). We investigated both shared and unique features of morphological diversification along this shared ecological gradient within the three different genera. Shared features of divergence serve as substantial evidence for common natural selective pressures shaping phenotypes (Cody and Mooney 1978; Harvey and Pagel 1991; Winemiller 1991, 1992; Robinson and Wilson 1994; Losos et al. 1998; Johnson and Belk 2001). Aspects of divergence that differ among species are attributed to unique histories among species (i.e., clade-specific effects, chance happenings, localized environmental differences).

\section{Methods \\ Collections}

All fish were collected using seines and dip nets. Two categories of populations are represented for each species: "predator" populations are sites where a given livebearer coexisted with piscivorous fish species, and "predatorfree" populations are sites where either no piscivorous

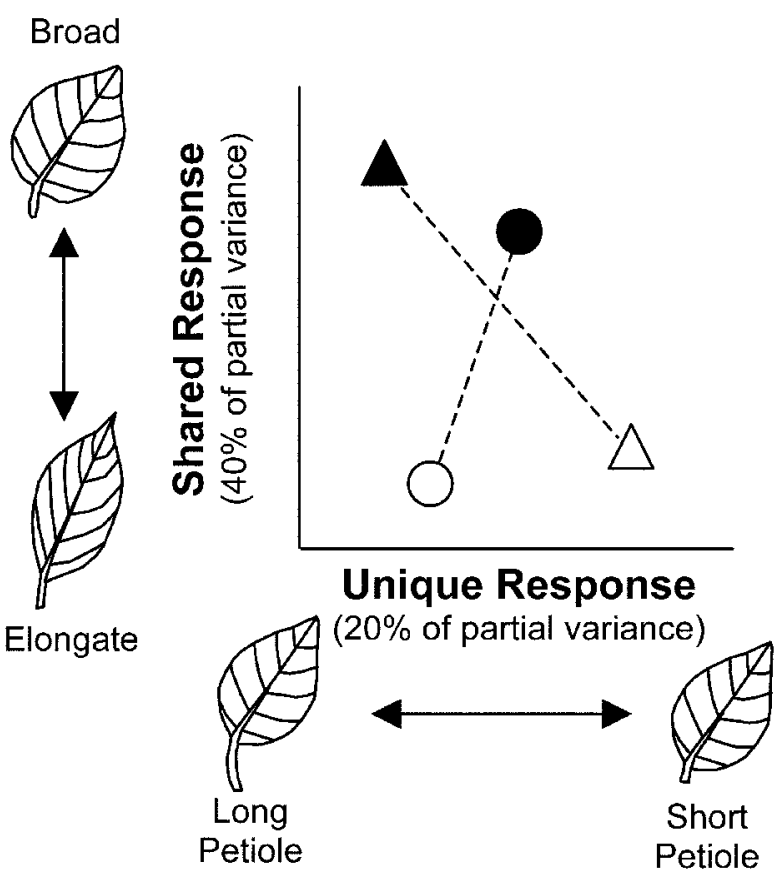

Figure 1: Hypothetical illustration of shared and unique features of leaf shape divergence across a light-availability gradient for two plant species. Circles $=$ species 1 ; triangles $=$ species 2 ; open symbols $=$ populations found in sunny environments; filled symbols = populations found in shaded environments. Both species exhibit relatively broad leaves in shaded environments but differ in response of petiole length across the gradient.

fishes occurred, or in the case of Poecilia reticulata, where only minor predatory fish co-occurred. Predator assemblages were surveyed using seines, cast nets, and dip nets. For each livebearer species, fish specimens were collected from six populations (three predator populations, three predator-free populations; table 2). In order to simplify analyses for the present paper, only adult male specimens are analyzed. For each species, more detailed morphometric analyses involving multiple age/gender classes will be presented in other papers.

We collected Gambusia affinis from freshwater ponds in Brazos County, Texas. Common predatory fishes found with G. affinis were native sunfishes (family Centrarchidae), including largemouth bass (Micropterus salmoides), green sunfish (Lepomis cyanellus), warmouth (Lepomis gulosus), longear sunfish (Lepomis megalotis), bluegill sunfish (Lepomis macrochirus), and white crappie (Pomoxis annularis). Collections of Bachyrhaphis rhabdophora were made in freshwater streams within two separate river drainages of northwestern Costa Rica near the Gulf of Nicoya (provided by J. B. Johnson). Two species of pi- 
Table 2: Summary information of fish collections for each species

\begin{tabular}{|c|c|c|c|c|c|}
\hline Species & $\begin{array}{l}\text { Geographic } \\
\text { region }\end{array}$ & Major fish predators & Population & $\begin{array}{c}\text { Predator } \\
\text { status }\end{array}$ & $N$ \\
\hline \multicolumn{6}{|c|}{ Gambusia affinis } \\
\hline \multirow[t]{6}{*}{$(N=140)$} & \multirow[t]{6}{*}{ Texas } & \multirow{6}{*}{$\begin{array}{l}\text { Piscivorous sunfish (Micropterus } \\
\text { salmoides, Lepomis spp., Pomoxis } \\
\text { annularis) }\end{array}$} & Autumn & NP & 23 \\
\hline & & & Hensel & NP & 23 \\
\hline & & & Riverside NP & NP & 23 \\
\hline & & & Krenek Tap & $\mathrm{P}$ & 23 \\
\hline & & & Riverside P & $\mathrm{P}$ & 23 \\
\hline & & & University Oaks & $\mathrm{P}$ & 25 \\
\hline \multicolumn{6}{|c|}{ Brachyrhaphis rhabdophora } \\
\hline \multirow[t]{6}{*}{$(N=147)$} & \multirow[t]{6}{*}{ Costa Rica } & \multirow{6}{*}{$\begin{array}{l}\text { Cichlid, Catfish } \\
\text { (Parachromis dovii, Rhamdia } \\
\text { guatemalensis) }\end{array}$} & 13, Jesus Maria & NP & 21 \\
\hline & & & 27, Canas & NP & 24 \\
\hline & & & 32, Jesus Maria & NP & 33 \\
\hline & & & 23, Canas & $\mathrm{P}$ & 25 \\
\hline & & & 28, Jesus Maria & $\mathrm{P}$ & 12 \\
\hline & & & 31, Canas & $\mathrm{P}$ & 32 \\
\hline \multicolumn{6}{|c|}{ Poecilia reticulata } \\
\hline \multirow[t]{6}{*}{$(N=138)$} & \multirow[t]{6}{*}{ Trinidad } & \multirow{6}{*}{$\begin{array}{l}\text { Cichlids, Characiforms (Crenicichla } \\
\text { alta, Cichlasoma bimaculatum, } \\
\text { Hoplias malabaricus, Astyanax } \\
\text { bimaculatus) }\end{array}$} & Upper Aqui River & NP & 8 \\
\hline & & & Upper Aripo River & NP & 20 \\
\hline & & & Upper Paria River & NP & 24 \\
\hline & & & Lower Arima River & $\mathrm{P}$ & 32 \\
\hline & & & Lower Aripo River & $\mathrm{P}$ & 38 \\
\hline & & & Lower Quare River & $\mathrm{P}$ & 16 \\
\hline
\end{tabular}

Note: $\mathrm{P}=$ piscivorous fish present; $\mathrm{NP}=$ no major piscivorous fish present. $N=$ sample size of adult males used in morphometric analyses. Population numbers for Brachyrhaphis rhabdophora refer to population designations by Johnson and Belk (2001). Jesus Maria and Canas are separate river drainages in Costa Rica.

scivorous fish, the cichlid Parachromis dovii (Cichlidae; synonymous with Cichlasoma dovii) and the catfish Rhamdia guatemalensis (Heptapteridae), occur in predator populations of B. rhabdophora (Johnson and Belk 2001). Individuals of $P$. reticulata were collected from mountain streams within three different drainages on the island of Trinidad (northern, Caroni, and Orupuche drainages; provided by F. Breden). Primary fish predators found in predator populations of $P$. reticulata are the pike cichlid Crenicichla alta, Cichlasoma bimaculatum (Cichlidae), Hoplias malabaricus (Erythrinidae), Hemibrycon dentatus, and Astyanax bimaculatus (Characidae). Predator-free populations of $P$. reticulata only contained the small killifish Rivulus hartii (Cyprinodontidae) as a potentially predatory fish (minor predator of juvenile guppies; for details, see Liley and Seghers 1975; Endler 1978; Mattingly and Butler 1994).

\section{Morphometrics}

For each species, we captured lateral images of adult male specimens. Images of live fish were captured for G. affinis, while images of preserved fish were captured for B. rhabdophora and P. reticulata. Images of G. affinis were obtained by placing live fish into a glass cage $(30 \mathrm{~mm}$ high $\times 40$ $\mathrm{mm}$ long $\times 5 \mathrm{~mm}$ wide) mounted in front of a video camera. The narrow cage prevented turning and restricted maneuverability, thus maintaining a constant angle of view. We captured live images for G. affinis to enable subsequent swimming performance trials (not presented in this study).

We digitized 10 landmarks on each lateral image using MorphoSys software, version 1.29 (Meacham 1993; fig. 2). Because we hypothesized that natural selection might favor a body morphology that increases fast-start escape speed in the presence of piscivorous fishes, we highlight in our figures the body region most responsible for generating accelerated bursts, the caudal peduncle (see fig. 2). Using our digitized landmarks, we conducted geometric morphometric analyses. Geometric morphometrics is a powerful tool for analyzing shape variation (Rohlf and Marcus 1993). The distinguishing feature of geometric morphometrics is that it retains information on spatial covariation among landmarks; traditional approaches use one-dimensional distances without consideration of where a given measurement is taken relative to others. We used tpsRegr software (Rohlf 2000) to obtain superimposed landmark coordinates. The tpsRegr program rotates, translates, and scales landmark coordinates into alignment via generalized least squares su- 


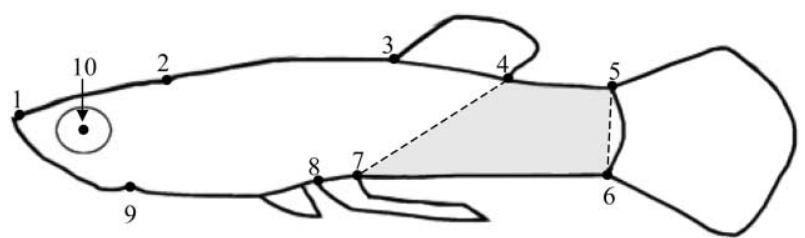

Figure 2: Landmarks used for morphometric analyses (Gambusia affinis depicted). The shaded region highlights the caudal peduncle.

perimposition (Bookstein 1991; Marcus et al. 1996). This technique removes size differences among specimens, although allometric relationships remain. Superimposed landmark configurations were used to calculate affine and nonaffine shape components (i.e., uniform components and partial warps) using tpsRegr. Affine components describe uniform spatial covariation in the $\mathrm{x}-\mathrm{y}$ plane, while nonaffine components describe inhomogeneous changes (local deformations). These shape variables (uniform components and partial warps) served as dependent variables describing body morphology in our statistical analyses described below.

\section{Statistical Analysis}

To investigate body shape variation, independent of allometry, we included a measure of body size as a covariate in our primary statistical model. We used centroid size as our estimate of overall body size, as is typical in geometric morphometrics (Bookstein 1991). Centroid size is the square root of the summed, squared distance of all landmarks from their centroid. In this study, centroid size was highly correlated with standard length $(r \geq 0.99, P<$ .0001 for each species). Statistical analyses were conducted using JMP software (version 4.04, SAS, Cary, N.C.) unless otherwise noted.

Shape data were tested for effects attributable to centroid size (covariate), predator regime, species, the interaction between predator regime and species, and populations nested within predator regime-species combinations. So a formal representation of our nested MANCOVA is

$$
\begin{aligned}
\text { Body shape }= & \text { Constant }+ \text { Centroid size } \\
& + \text { Predator regime }+ \text { Species } \\
& + \text { Predator regime } \times \text { Species } \\
& + \text { Population (Predator regime } \times \text { Species) }
\end{aligned}
$$

The factors of most interest were predator regime (shared morphological divergence among all species), species (effects due to different evolutionary histories), and the interaction between predator regime and species (unique aspects of divergence among species). To evaluate the relative importance of these three factors in the model, we estimated effect size using Wilks's partial $\eta^{2}$, a measure of partial variance explained by a given factor (see appendix). For each factor, MANCOVA generates canonical variates describing morphological variation designed to have optimal association with a given factor. Using these canonical axes, we produced thin-plate spline transformations of landmark positions (using tpsRegr software) to visualize shape variation along the axes. We magnified thin-plate spline transformations $(\times 2)$ to more clearly illustrate morphological differences described by the axes.

Since we included size as a covariate, we tested for heterogeneity of slopes and found that slopes only varied among species but not among predator regimes or the predator regime by species interaction. This finding indicated that multivariate allometry differed between species. We conducted the analysis with and without the interaction term of centroid size $\times$ species and examined significance of effects and loadings of canonical axes. Inclusion of the interaction term had no effect on the significance of main effects, no discernible effects on canonical loadings of axes involving the predator regime effect (i.e., axes describing shared and unique divergence), and minimal effects on canonical loadings of axes derived from the species effect. Since results were highly similar with and without this interaction term in the model, we only present results from an analysis including the term. This interaction term was centered (i.e., continuous variable converted to deviation scores from a mean of 0 ) to provide a meaningful hypothesis test of the species term by avoiding multicollinearity problems between the species term and the interaction term (Aiken and West 1991; Tabachnick and Fidell 2001).

To provide an intuitive metric regarding the magnitude of particular effects (e.g., percent of fish correctly classified into predator regime), we performed discriminant function analyses (DFA). Each DFA used the shape variables (uniform components and partial warps) as the dependent variables and one particular factor as the independent variable. Thus, we examined to what degree we could predict a fish's classification (e.g., species, predator regime) based on its morphology. We performed DFA to classify fish by species irrespective of predator regime, predator regime irrespective of species, and species-predator regime combinations (i.e., six factors). The first DFA evaluated the magnitude of morphological differences between species. The second DFA examined the magnitude of shared features of morphological diversification between predator regimes. The third DFA was conducted to assess the in- 
Table 3: Results of MANCOVA examining shape variation among the three species

\begin{tabular}{llcccc}
\hline Test for & \multicolumn{1}{c}{ Factor } & \multicolumn{1}{c}{$F$} & df & $P$ & $\begin{array}{c}\text { Partial variance } \\
\text { explained (\%) }\end{array}$ \\
\hline Shared divergence & Predator regime $(\mathrm{PR})$ & 14.25 & 16,389 & $<.0001$ & 36.9 \\
Unique histories & Species $(\mathrm{S})$ & 82.08 & 32,778 & $<.0001$ & 77.1 \\
Unique divergence & $\mathrm{PR} \times \mathrm{S}$ & 7.07 & 32,778 & $<.0001$ & 22.5 \\
\hline
\end{tabular}

Note: $F$ was approximated using Wilks's $\lambda$ values for the species factor and the interaction term. Partial variance explained by each effect was estimated using Wilks's partial $\eta^{2}$ (see appendix).

crease in predictive ability over the second DFA when both shared and unique aspects of divergence were used to predict predator regime classification. As a cross-validation technique, we conducted DFAs using jackknife sampling. This procedure removed one individual from the data set, classified that individual based on a DFA of the remaining data, returned the individual to the data set, and then repeated this process for each individual. DFAs using jackknife sampling were performed using SYSTAT (version 10, SPSS, Chicago).

\section{Results}

In our nested MANCOVA, we found significant effects of centroid size $(F=3.88, \mathrm{df}=16,389, P<.0001)$, the interaction between centroid size and species (Wilks's $\lambda=0.60, P<.0001)$, and populations nested within the predator regime $\times$ species interaction (Wilks's $\lambda=0.07$, $P<.0001)$. In regard to the factors in which we were most interested, we found significant effects for all factors (table 3 ). The predator regime effect indicated significant morphological divergence between predatory environments, regardless of species. The canonical variate derived from this effect described a shared axis of diversification for the three species (fig. 3). Examination of the predator regime canonical loadings revealed four major morphological shifts: fish found in predator populations exhibited a relatively more elongate body, longer and deeper caudal peduncle, shallower anterior body/head region, and lower position of the eye. This common morphological trend between predator regimes existed for three different species despite large morphological differences between species (table 3).

Unique aspects of morphological divergence between predator regimes were also evident (interaction term; table 3). By graphically combining canonical axes describing shared and unique features of divergence, we could evaluate both aspects of diversification within one multidimensional trait space (fig. 4). The first canonical axis derived from the interaction term described a morphological shift between predator regimes that was opposite in direction for Gambusia affinis and Poecilia reticulata and that Brachyrhaphis rhabdophora did not share (fig. 4). A major aspect of this shift involved a lower position of the posterior insertion of the anal fin (point 7 in fig. 2 ) in predator populations of G. affinis and predator-free populations of $P$. reticulata. That is, G. affinis exhibited a deepening of the entire caudal peduncle (i.e., from anal fin to caudal fin insertion) in predator environments, while $P$. reticulata primarily deepened near the caudal fin insertion and exhibited a relatively shallow midbody in predator populations. This axis also largely described a difference in morphology between G. affinis and the other two species; G. affinis, as a species, exhibited a higher position of the posterior insertion of the anal fin (fig. 4). The second canonical axis derived from the interaction term reflected a shift between predator regimes in $B$. rhabdophora that is not shared by the other species. This axis primarily described changes in dorsal fin insertion length, whereby $B$. rhabdophora exhibited a relatively longer dorsal fin insertion length in predator environments (fig. 4). This axis also described a difference between B. rhabdophora and the other two species, with $B$. rhabdophora, as a species, having a relatively longer dorsal fin insertion length (fig. 4).

Based on morphology, our first DFA classified fish by species, with the null hypothesis being one-third correctly classified by chance. The DFA classified all 425 fish to the proper species with a probability of $1.0(100 \%$ correct, Wilks's $\lambda=0.005, P<.0001$ ), indicating clear morphological differences between species. Our second DFA predicted predator regime of origin for each fish based on body morphology, with the null hypothesis being 50\% correctly classified by chance. Despite the marked difference in body shape among species, DFA correctly classified 327 of 425 fish (76.9\%) into the proper predator regime, irrespective of species $(F=17.83, \mathrm{df}=16,408, \quad P<$ $.0001)$. Thus, all species differed in shape across predator regimes in so similar a manner that a great majority of individual fish could be correctly classified into their predator regime regardless of species differences in shape. Our third DFA classified fish into species-predator regime combinations (i.e., six different combinations). This DFA incorporated both shared and unique elements of diver- 

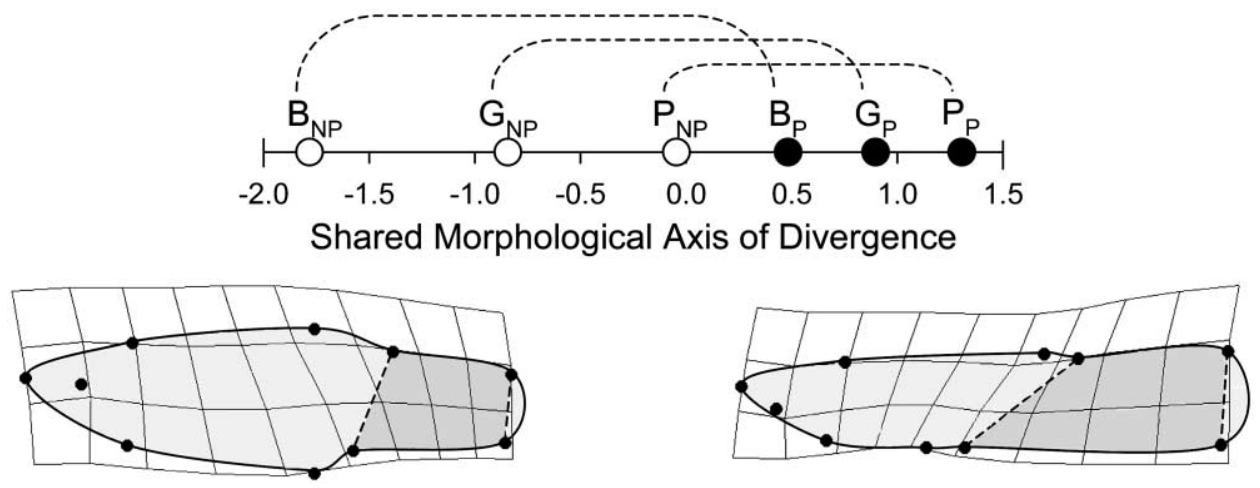

Figure 3: Shared features of morphological diversification between predator regimes among three species of livebearers. Centroids for both predatory environments are depicted for each species on the predator regime canonical axis derived from MANCOVA. B = Brachyrhaphis rhabdophora; $G=$ Gambusia affinis; $P=$ Poecilia reticulata. Subscripts denote predator regime as in table 2. Dotted lines connect predator and predator-free centroids of each species. Thin-plate spline transformations (magnified $\times 2$ ) were generated with tpsRegr software (Rohlf 2000) using landmark coordinates and canonical scores and illustrate the morphological variation described by this axis.

gence and correctly assigned 345 of 425 fish (81.2\%) into the proper species-predator regime category (Wilks's $\lambda=0.002, P<.0001)$. Thus, an increase of $4.3 \%$ in predictive ability occurred when unique aspects of divergence (species-specific responses) were incorporated in addition to the shared features.

\section{Discussion}

Due to the combined influences of common selection regimes and unique evolutionary histories, we might expect to observe both shared and unique features of diversification when multiple groups of organisms experience similar environmental circumstances (e.g., Harvey and Pagel 1991; Travisano et al. 1995; Schluter 2000; Ruzzante et al. 2003). In this study, we explicitly evaluated and quantified both shared and unique aspects of morphological divergence between predatory environments for three species of livebearing fish. We found strong evidence for a role of natural selection in generating a common pattern of morphological divergence for the three species. Yet, we also observed unique features of divergence within each species, suggesting a role for historical contingency in the observed evolutionary outcomes.

\section{Shared Features of Diversification}

Our analysis revealed a strong, shared pattern of diversification among the three different species. Despite considerable morphological differences between species, we could correctly predict the predator regime of origin for
$76.9 \%$ of fish, irrespective of species, based on body shape. This general pattern persisted despite the species inhabiting different habitat types (e.g., ponds, streams), different geographic regions (Texas, Costa Rica, Trinidad), and environments with different predatory fish (e.g., sunfish, cichlids). Due to the strong footprint of unique histories evident in this study (i.e., large magnitude of differences in body form among species), it is quite surprising that we observed such a clear generalized response across divergent predator regimes. The generality of this trend across three distantly related species strongly suggests that common selective forces involving predation from piscivorous fishes have produced convergent patterns of morphological diversification (Cody and Mooney 1978; Harvey and Pagel 1991; Winemiller 1991, 1992; Robinson and Wilson 1994; Losos et al. 1998; Johnson and Belk 2001).

Further, the nature of the shared morphological differences between predator and predator-free populations may largely reflect changes in body shape associated with changes in fast-start escape speeds. Fast starts (sudden bursts of unsteady swimming activity, often termed "cstarts") are employed by many fish when escaping predation and are generated by the posterior body/caudal fin portion of fishes (Howland 1974; Eaton et al. 1977; Webb 1982, 1984, 1986; Harper and Blake 1990; Walker 1997). We hypothesized that, regardless of species, natural selection might favor a body morphology that increases faststart escape speed in the presence of piscivorous fishes. A major aspect of the shared features of morphological divergence in this study involved a relatively larger caudal peduncle in prey species from predator populations (see 


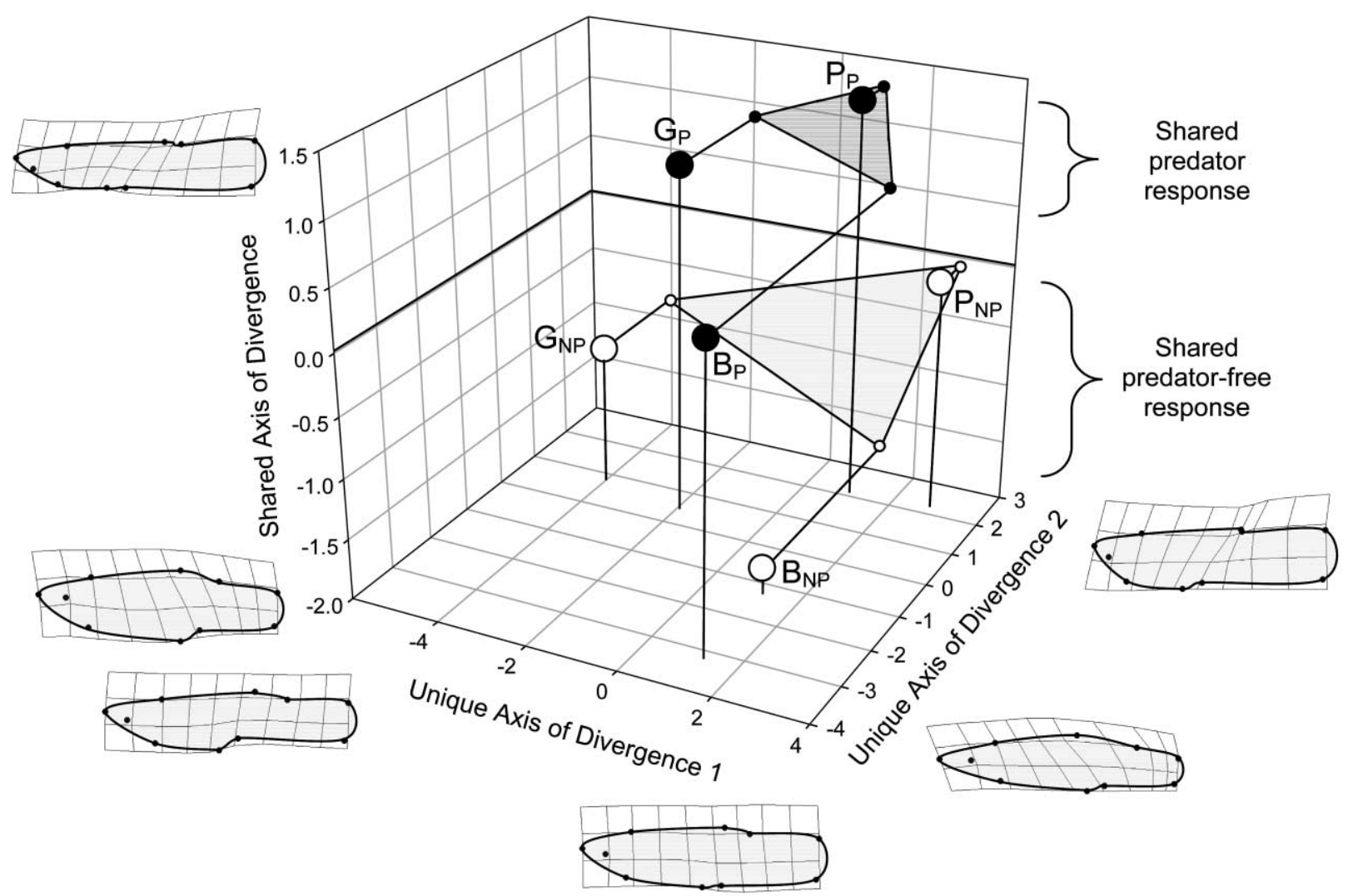

Figure 4: Shared and unique axes of morphological diversification between predator environments for the three species. The vertical axis depicts the predator regime canonical axis. Horizontal axes depict the two canonical axes derived from the interaction term of the MANCOVA. Species and predator regime abbreviations follow figure 3. Filled symbols = predator centroids; open symbols = predator-free centroids. Thin-plate spline transformation grids illustrate morphological differences described by each axis (magnified $\times 2$ ). Convex hulls (shaded triangles) were projected to help visualize the shared nature of divergence across predator regimes.

fig. 3), possibly increasing fast-start escape speeds and thus survival with predators. Recent work supports this hypothesis. In Poecilia reticulata, individuals from predator populations (including $\mathrm{F}_{2}$ laboratory-reared individuals) exhibit higher fast-start escape speeds and survive predatory encounters better than fish from predator-free populations (O'Steen et al. 2002; Ghalambor et al., in press; S. O'Steen and A. F. Bennett, unpublished manuscript). Furthermore, Gambusia affinis individuals collected from predator populations exhibit faster escape speeds than individuals collected from predator-free populations (Langerhans et al., in press). Body shape also significantly predicts escape speed in G. affinis, whereby fish with relatively predator-associated morphologies (e.g., larger caudal peduncle) exhibit higher fast-start speeds regardless of predator regime of origin (Langerhans et al., in press). However, other selective pressures may also contribute to the shared features of morphological divergence. These other factors might involve sustainable locomotion, predator detection (e.g., lower position of eye-most predators attack livebearers from below), avoiding detection by predators, and foraging shifts among other potential targets of selection, all of which require further study.

\section{Unique Features of Diversification}

Observed differences between species in the nature of morphological divergence across the environmental gradient can largely be seen as variations on a general theme. In the present study, species-specific responses to the gradient were of lesser magnitude than shared responses (i.e., using Wilks's partial $\eta^{2}$ as an estimate of effect size; table 3). Further, if species-specific responses were of great importance, then a large gain in discriminatory ability would 
have resulted when these unique responses were incorporated with shared responses in the DFA. Yet incorporating unique features in DFA resulted in only a $4.3 \%$ increase in correct prediction of predator regime. Thus it seems that the influence of unique evolutionary histories was largely outweighed by shared selective pressures in creating the observed patterns of divergence. That is not to say unique features of diversification are unimportant; evaluation of these unique elements could prove useful in understanding the generality of evolutionary divergence and in producing hypotheses concerning localized features of diversification.

Species-specific aspects of diversification across the common ecological gradient suggest that differences in evolutionary histories among the three species played a role in the evolutionary outcomes. Unique features of divergence might indicate that multiple body forms can enhance fitness in the presence of piscivorous fishes (or in the absence of piscivorous fishes) but also that some selective pressures associated with divergent predator regimes might vary between species (e.g., different predator species might cause different selection). Additionally, unique aspects of divergence might reflect the imprints of unique selective events, phylogenetic constraints, or chance historical events peculiar to each species, producing a tendency to diverge in different manners.

The first unique axis of diversification primarily described differences in response between G. affinis and $P$. reticulata involving the position of the posterior insertion of the anal fin (fig. 4). The opposite nature of divergence for these two species might actually reflect two alternative routes of achieving one common solution: increased relative surface area of the caudal peduncle in predatory environments (see "Results"). This type of result, analogous but not homologous divergence, might be generally expected for more distantly related taxa, producing unique features of divergence that show functional equivalence (see also Langerhans et al. 2003). The second unique axis of diversification primarily described aspects of divergence exclusively found in Brachyrhaphis rhabdophora, predominantly a shift toward longer dorsal fin insertion lengths in predator populations. This shift may signify an increase in dorsal fin size in predatory environments for B. rhabdophora, which could further serve to increase surface area involved in generating fast-start escape bursts. It is possible that the unique history of B. rhabdophora, which apparently led to relatively longer dorsal fin insertion lengths compared with other species in the study, provided the unique opportunity to diverge in this feature across the selection regimes. Only by evaluation of unique features of diversification did these hypotheses arise, pointing toward future research avenues.

\section{Evolutionary Convergence and Phylogenetic Effects}

The shared patterns of phenotypic divergence observed in this study appear to represent convergent evolutionary responses to a common ecological problem. Multiple lines of evidence suggest that the shared features of divergence indeed represent independent evolutionary events resulting in similar phenotypic outcomes. First, we have reason to believe that observed patterns of morphological divergence have genetic bases within each species, thus representing heritable changes in phenotype among predatory environments. For G. affinis, morphological differences observed in wild-caught fish were retained in offspring reared under common-garden laboratory conditions using populations included in this study (Langerhans et al., in press). For B. rhabdophora and P. reticulata, heritable phenotypic differences across predator regimes have previously been documented (Reznick 1982; Breden et al. 1987; Reznick and Bryga 1996; Johnson 2001a; O'Steen et al. 2002), and phenotype divergence has apparently evolved independently multiple times within these species (Fajen and Breden 1992; Endler 1995; Houde 1997; Reznick et al. 1997; Johnson 2001a, 2001b; F. Breden and J. S. Taylor, unpublished manuscript). Second, the three species examined in this study comprise distantly related phylogenetic lineages (Rosen and Bailey 1963; Parenti and Rauchenberger 1989; Ghedotti 2000). Thus, the shared features of phenotypic divergence in these three species most likely represent convergent evolution, or more precisely, "convergent divergence."

However, there is an alternative explanation for the shared features of diversification, that of a phylogenetic effect. That is, the effect of unique histories not only might cause different responses to common selective pressures but also might cause shared responses within clades (Harvey and Pagel 1991). Thus, it is possible that all Poeciliid fish contain similar genetic architectures that predispose them to evolve along parallel trajectories in response to similar selective pressures (i.e., genetic lines of least resistance; Schluter 1996a). An increase in the phylogenetic breadth of investigations into morphological divergence across predation environments in fishes, as well as examination of genetic variances/covariances, should help resolve this issue.

\section{Future Prospects of the Shared and Unique Framework}

The general framework for the investigation of shared and unique features of diversification described in this article should have broad applicability across diverse systems and be useful for assessing the relative roles of unique histories and common natural selective forces in driving evolutionary diversification. The approach could even provide 
new insights into classically studied systems in evolutionary biology such as stickleback species pairs (Gasterosteus spp.) in postglacial lakes (reviewed in Schluter and McPhail 1992; McPhail 1993, 1994) and Anolis lizard radiations on islands of the Greater Antilles (reviewed in Williams 1983; Losos 1992; Losos et al. 1998). The remarkable convergence in patterns of phenotypic divergence across habitats observed in these systems is well established; however, potentially unique aspects of divergence-variations on the theme-have largely been overlooked.

For example, species of Anolis lizards found in similar habitats on different islands in the Greater Antilles exhibit striking morphological similarities, termed "ecomorphs" (e.g., trunk-ground, crown-giant, twig). These ecomorphs have evolved independently on the four islands (Williams 1983; Losos et al. 1998; Jackman et al. 1999). Within the framework described here, researchers could explicitly address - and quantify in comparable units_-the shared and unique features of morphological divergence between habitats observed among islands. This would reveal the relative magnitudes of common ecology-phenotype associations, effects due to unique histories on different islands (potentially reflecting phylogenetic influence of initial colonists), and unique divergence among habitats due to the unique histories. Unveiling the nature and relative importance of these factors should provide a more complete understanding of adaptive radiation in these lizards and could lead to yet unseen research directions in this muchstudied system.

It should be pointed out that the framework described in this article is relatively mechanistic in focus. That is, for the approach to be applied, organisms must inhabit alternative environments that presumably differ in selective pressures; the researcher must choose an environmental gradient a priori. Through this requirement, the approach emphasizes the discovery of general gradients that are shared by multiple organisms (e.g., water velocity in fishes, light availability in plants, variable food resources in diverse taxa). Due to this mechanistic focus, the framework should serve as a powerful tool in elucidating causes, not only patterns, of evolutionary divergence.

This framework, however, is not without limits. One limitation we foresee involves the amount of disparity between groups of organisms examined. To combine species into a single trait space, the species must share equivalent traits. Assuming equivalent traits, the species also must not differ so dramatically in the details of these characters as to prevent identification of shared features of divergence across a common gradient. Thus, evaluation of extremely distantly related organisms could prove difficult in certain cases, although certain characters are often comparable among disparate organisms (e.g., clutch size, behavioral avoidance). Creative indices of characters could alleviate these limitations in certain cases. In particular studies, researchers could even obtain "species-free" residuals of phenotype values to eliminate drastic differences between species before analyzing shared and unique aspects of diversification among the disparate species. Furthermore, to explicitly address whether observed features of divergence represent independent adaptations, additional analyses in a more phylogenetic context might often be required; however, this framework can evaluate shared and unique features of divergence among clades.

We note that a few studies have independently converged upon the general underpinnings of the framework described here (Van Buskirk 2002; Ruzzante et al. 2003). These studies represent a large leap forward in the investigation of shared and unique features of diversification and attest to the utility of the approach. In particular, these studies explicitly examined unique aspects of divergencea feature often neglected-while simultaneously addressing the major aspects of shared divergence. However, these studies did not describe a general framework to guide future research in this field. Nor have previous authors compared the nature and relative magnitudes of shared and unique aspects of divergence by examining canonical variates specifically designed to describe these features. Through such explicit quantification of both shared and unique aspects of diversification, we may gain greater understanding of the relative roles of natural selection and historical contingency in evolution.

Among the most remarkable findings in evolutionary biology are examples of common phenotypic outcomes observed across a shared ecological gradient among organisms of different phylogenetic backgrounds. Such "convergent divergence" provides strong evidence for a powerful role of natural selection in evolutionary diversification (e.g., Losos 1990; Harvey and Pagel 1991; Winemiller 1991; Robinson and Wilson 1994; Smith and Skúlason 1996; Losos et al. 1998; Johnson and Belk 2001). However, understanding the relative importance of unique histories in producing unique responses across shared selection regimes should not be neglected (Endler 1982; Van Buskirk 2002; Langerhans et al. 2003; Ruzzante et al. 2003). Without quantification of unique responses, the general trends cannot be fully understood or appreciated. Further, the discovery of unique features of divergence might often lead to new hypotheses and unexpected avenues of research.

\section{Acknowledgments}

We thank A. Langerhans, C. Layman, H. Prestridge, and M. Shokrollahi for assistance collecting specimens and sampling fish assemblages. We are grateful to F. Breden 
and J. Johnson for providing specimens of Poecilia reticulata and Brachyrhaphis rhabdophora, respectively. D. Adams, L. Harmon, J. Johnson, J. Losos, the Losos Lab group, and an anonymous reviewer provided valuable comments that improved the manuscript. Support for this work was provided in part by a Sustainable Coastal Margins Program fellowship and a Texas Water Resources Institute Mills Scholarship to R.B.L. and National Science Foundation award DEB-9618702/9908528 to T.J.D.

\section{APPENDIX}

\section{Evaluating Relative Importance of Factors in Multivariate Analysis}

Several measures of multivariate association have been devised to assess the explanatory strength and relative importance of independent variables in multivariate analyses (Wilks 1932; Hotelling 1936; Shaffer and Gillo 1974; Cramer and Nicewander 1979; Muller and Peterson 1984; Olejnik and Algina 2000; Tabachnick and Fidell 2001; Rencher 2002). For MANOVA/MANCOVA designs, some of the most common measures of effect size estimate the proportion of partial variance explained by factors using the standard multivariate test statistics Wilks's $\lambda$, Pillai's trace $(V)$, and Hotelling-Lawley's trace $(U)$. These measures of effect size serve as multivariate analogues to the univariate measure of partial variance explained by a given independent variable, partial $\eta^{2}$ :

$$
\text { partial } \eta^{2}=\frac{\mathrm{SS}_{\text {effect }}}{\mathrm{SS}_{\text {effect }}+\mathrm{SS}_{\text {error }}}
$$

Partial $\eta^{2}$ evaluates the explanatory ability of a factor relative to unexplained variation. Because this value represents proportion of partial variance rather than total variance, the sum of partial $\eta^{2}$ for all independent variables in a model can exceed 1.0. This fact does not hinder in any way the ability to compare the relative importance of particular factors within a given model; it simply must be interpreted as the relative importance of a factor compared to residual variation unexplained by the statistical model.

All multivariate measures of explained partial variance estimate the above quantity (eq. [1]) using sums-ofsquares cross-products matrices rather than univariate sums of squares. For independent variables with only two groups (e.g., predator regime factor in this article), all standard multivariate estimates are equivalent and reduce directly to a matrix version of the univariate equation. However, for independent variables with more than two groups (e.g., species factor in this article), an adjustment must be made to correct for a bias toward overestimation of explained partial variance due to the additional levels (and thus additional canonical variates potentially explaining variance). This adjustment is meant to place all factors in a model on a common scale in order to assess their relative importance. The three most common multivariate measures of partial variance explained are

$$
\begin{aligned}
\text { Wilks's partial } \eta^{2} & =1-\lambda^{1 / s}, \\
\text { Pillai's partial } \eta^{2} & =\frac{V}{s}, \\
\text { Hotelling-Lawley's partial } \eta^{2} & =\frac{U}{U+s},
\end{aligned}
$$

where $s=\min \left(p, \mathrm{df}_{\text {effect }}\right), p=$ number of dependent variables, and $\mathrm{df}_{\text {effect }}=$ degrees of freedom for the particular factor of interest. For factors with only two groups, $s=$ 1 , and all measures of partial $\eta^{2}$ are equal. For a given factor with more than two groups, the values generally exhibit the following ranking: Pillai's partial $\eta^{2}<$ Wilks's partial $\eta^{2}<$ Hotelling-Lawley's partial $\eta^{2}$.

Since these measures are point estimates (i.e., no associated variance), assessing relative importance of factors with similar values is problematic. Additionally, when two factors are similar in one measure of partial $\eta^{2}$, their rank order might differ for another measure (e.g., factor 1 might appear more important using Wilks's partial $\eta^{2}$, but factor 2 might appear more important using Pillai's partial $\eta^{2}$ ). When researchers wish to assess whether factors differ significantly in their effect size, one possible route is to use jackknife sampling and rank congruence to evaluate significance. That is, differences in effect size between factors would be considered significant only if no overlap existed between jackknifed ranges for each particular measure and rank order was equivalent for all three measures. While researchers should always report methods of deriving significance (e.g., using the above criteria), we suggest that when all measurements of partial $\eta^{2}$ accord with each other, only values for Wilks's partial $\eta^{2}$ need be presented. This is because Wilks's partial $\eta^{2}$ is the most commonly reported statistic in research fields that frequently report effect sizes in multivariate analyses to compare relative importance of factors (e.g., applied statistics, psychology, medicine); it typically approximates the average of the other two common partial $\eta^{2}$ values and is derived from Wilks's $\lambda$, which is already the most commonly used test statistic for independent variables in MANOVA/MANCOVA designs. For the MANCOVA conducted in this study, all three measures of effect size, their jackknifed ranges, and rank order of factors for each measure are presented in table Al. In this model, using the aforementioned criteria, partial $\eta^{2}$ values for all factors were significantly different from one another. 
Table A1: Shape variation among the three livebearing fish species

\begin{tabular}{lcccccc}
\hline Factor & Wilks's partial $\eta^{2}$ & Rank & Pillai's partial $\eta^{2}$ & Rank & $\begin{array}{c}\text { Hotelling-Lawley's } \\
\text { partial } \eta^{2}\end{array}$ & Rank \\
\hline Predator regime (PR) & $.3695(.3542-.3768)$ & 2 & $.3695(.3542-.3768)$ & 2 & $.3695(.3542-.3768)$ & 2 \\
Species (S) & $.7715(.76386-.7752)$ & 1 & $.7319(.7180-.7360)$ & 1 & $.8052(.8009-.8097)$ & 1 \\
PR $\times$ S & $.2252(.2202-.2311)$ & 3 & $.2170(.2122-.2223)$ & 3 & $.2333(.2279-.2398)$ & 3 \\
Population [PR $\times$ S ] & $.1947(.1929-.1967)$ & 4 & $.1738(.1721-.1752)$ & 4 & $.2215(.2197-.2247)$ & 4 \\
Centroid size (C) & $.1376(.1292-.1431)$ & 5 & $.1376(.1292-.1431)$ & 5 & $.1376(.1292-.1431)$ & 5 \\
$\mathrm{C} \times \mathrm{S}$ & $.0961(.0907-.1028)$ & 6 & $.0951(.0895-.1016)$ & 6 & $.0970(.0919-.1041)$ & 6 \\
\hline
\end{tabular}

Note: Three measures of effect size (i.e., proportion of partial variance explained) for each factor in the MANCOVA examining shape variation among the three livebearing fish species (all effects are significant; $P<.0001$ ). Numbers in parentheses are jackknifed ranges obtained by conducting the analysis excluding one case at a time until all cases were excluded once. Jackknifed analyses were conducted using SYSTAT (version 10, SPSS, Chicago).

\section{Literature Cited}

Aiken, L. S., and S. G. West. 1991. Multiple regression: testing and interpreting interactions. Sage, Newbury Park, Calif.

Ballaré, C. L. 1999. Keeping up with the neighbours: phytochrome sensing and other signalling mechanisms. Trends in Plant Science 4:97-102.

Bookstein, F. L. 1991. Morphometric tools for landmark data. Cambridge University Press, New York.

Breden, F., and G. Stoner. 1987. Male predation risk determines female preference in the Trinidad guppy. Nature 329:831-833.

Breden, F., M. A. Scott, and E. Michel. 1987. Genetic differentiation for antipredator behavior in the Trinidad guppy, Poecilia reticulata. Animal Behaviour 35:618620.

Bussing, W. A. 1998. Peces de las aguas continentales de Costa Rica. Editorial de la Universidad de Costa Rica, San Jose.

Cadle, J. E., and H. W. Greene. 1993. Phylogenetic patterns, biogeography, and the ecological structure of Neotropical snake assemblages. Pages 281-293 in R. Ricklefs and D. Schluter, eds. Species diversity in ecological communities: historical and geographical perspectives. University of Chicago Press, Chicago.

Cody, M. L., and H. A. Mooney. 1978. Convergence versus nonconvergence in Mediterranean-climate ecosystems. Annual Review of Ecology and Systematics 9:265-321.

Cramer, E. M., and W. A. Nicewander. 1979. Some symmetric, invariant measures of multivariate association. Psychometrika 44:43-54.

Donohue, K., D. Messiqua, E. H. Hammond-Pyle, M. S. Heschel, and J. Schmitt. 2000. Evidence of adaptive divergence in plasticity: density- and site-dependent selection on shade-avoidance responses in Impatiens capensis. Evolution 54:1956-1968.

Downhower, J. F., L. P. Brown, and M. L. Matsui. 2000.
Life history variation in female Gambusia hubbsi. Environmental Biology of Fishes 59:415-428.

Eaton, R. C., R. A. Bombardieri, and D. L. Meyer. 1977. The Mauthner-initiated startle response in teleost fish. Journal of Experimental Biology 66:65-81.

Endler, J. A. 1978. A predator's view of animal color patterns. Evolutionary Biology 11:319-364.

- 1980. Natural selection on color patterns in Poecilia reticulata. Evolution 34:76-91.

- 1982. Convergent and divergent effects of natural selection on color patterns in two fish faunas. Evolution $36: 178-188$.

- 1983. Natural and sexual selection on color patterns in poeciliid fishes. Environmental Biology of Fishes 9:173-190.

- 1995. Multiple-trait coevolution and environmental gradients in guppies. Trends in Ecology \& Evolution 10:22-29.

Fajen, A., and F. Breden. 1992. Mitochondrial DNA sequence variation among natural populations of the Trinidadian guppy, Poecilia reticulata. Evolution 46:14571465.

Ghalambor, C. K., D. N. Reznick, and J. A. Walker. In press. Constraints on adaptive evolution: the functional trade-off between reproduction and fast-start swimming performance in the Trinidadian guppy (Poecilia reticulata). American Naturalist.

Ghedotti, M. J. 2000. Phylogenetic analysis and taxonomy of the poecilioid fishes (Teleostei: Cyprinodontiformes). Zoological Journal of the Linnean Society 130:1-53.

Gould, S. J. 1989. Wonderful life: the Burgess Shale and the nature of history. Norton, New York.

Gould, S. J., and D. S. Woodruff. 1990. History as a cause of area effects: an illustration from Cerion on Great Inagua, Bahamas. Biological Journal of the Linnean Society 40:67-98.

Harper, D. G., and R. W. Blake. 1990. Fast-start performance of rainbow trout Salmo gairdneri and northern pike Esox lucius. Journal of Experimental Biology 150: 321-342. 
Harvey, P. H., and M. D. Pagel. 1991. The comparative method in evolutionary biology. Oxford University Press, Oxford.

Hendry, A. P., and M. T. Kinnison. 2001. An introduction to microevolution: rate, pattern, process. Genetica 112: $1-8$.

Hotelling, H. 1936. Relations between two sets of variates. Biometrika 28:321-377.

Houde, A. E. 1997. Sex, color, and mate choice in guppies. Princeton University Press, Princeton, N.J.

Howland, H. C. 1974. Optimal strategies for predator avoidance: the relative importance of speed and maneuverability. Journal of Theoretical Biology 47:333350.

Huey, R. B., G. W. Gilchrist, M. L. Carlson, D. Berrigan, and L. Serra. 2000. Rapid evolution of a geographic cline in size in an introduced fly. Science 287:308-309.

Jackman, T. R., A. Larson, K. de Queiroz, and J. B. Losos. 1999. Phylogenetic relationships and tempo of early diversification in Anolis lizards. Systematic Biology 48: 254-285.

Jennions, M. D., and S. R. Telford. 2002. Life-history phenotypes in populations of Brachyrhaphis episcopi (Poeciliidae) with different predator communities. Oecologia (Berlin) 132:44-50.

Johannesson, K. 2003. Evolution in Littorina: ecology matters. Journal of Sea Research 49:107-117.

Johnson, J. B. 2001a. Adaptive life-history evolution in the livebearing fish Brachyrhaphis rhabdophora: genetic basis for parallel divergence in age and size at maturity and a test of predator-induced plasticity. Evolution 55:14861491.

- 2001b. Hierarchical organization of genetic variation in the Costa Rican livebearing fish Brachyrhaphis rhabdophora (Poeciliidae). Biological Journal of the Linnean Society 72:519-527.

- 2002. Evolution after the flood: phylogeography of the desert fish Utah chub. Evolution 56:948-960.

Johnson, J. B., and M. C. Belk. 2001. Predation environment predicts divergent life-history phenotypes among populations of the livebearing fish Brachyrhaphis rhabdophora. Oecologia (Berlin) 126:142-149.

Krumholz, L. 1963. Relationships between fertility, sex ratio, and exposure to predation in populations of the mosquitofish, Gambusia manni at Bimini, Bahamas. Internationale Revue der gesamten Hydrobiologie 48:201256.

Langerhans, R. B., C. A. Layman, A. K. Langerhans, and T. J. DeWitt. 2003. Habitat-associated morphological divergence in two Neotropical fish species. Biological Journal of the Linnean Society 80:689-698.

Langerhans, R. B., C. A. Layman, A. M. Shokrollahi, and
T. J. DeWitt. In press. Predator-driven phenotypic diversification in Gambusia affinis. Evolution.

Lardner, B. 2000. Morphological and life history responses to predators in larvae of seven anurans. Oikos 88:169180.

Liley, N. R., and B. H. Seghers. 1975. Factors affecting the morphology and behavior of guppies in Trinidad. Pages 92-118 in G. P. Baerends, C. Beer, and A. Manning, eds. Function and evolution in behaviour. Clarendon, Oxford.

Losos, J. B. 1990. The evolution of form and function: morphology and locomotor performance in West Indian Anolis lizards. Evolution 44:1189-1203.

. 1992. The evolution of convergent structure in Caribbean Anolis communities. Systematic Biology 41: 403-420.

Losos, J. B., T. R. Jackman, A. Larson, K. de Queiroz, and L. Rodriguez-Schettino. 1998. Contingency and determinism in replicated adaptive radiations of island lizards. Science 279:2115-2118.

Magurran, A. E., B. H. Seghers, G. R. Carvalho, and P. W. Shaw. 1992. Behavioral consequences of an artificial introduction of guppies (Poecilia reticulata) in North Trinidad: evidence for the evolution of antipredator behavior in the wild. Proceedings of the Royal Society of London B 248:117-122.

Magurran, A. E., B. H. Seghers, P. W. Shaw, and G. R. Carvalho. 1995. The behavioral diversity and evolution of guppy, Poecilia reticulata, populations in Trinidad. Advances in the Study of Behavior 24:155-202.

Marcus, L. F., M. Corti, A. Loy, G. J. P. Naylor, and D. E. Slice. 1996. Advances in morphometrics. Plenum, New York.

Matos, M., T. Avelar, and M. R. Rose. 2002. Variation in the rate of convergent evolution: adaptation to a laboratory environment in Drosophila subobscura. Journal of Evolutionary Biology 15:673-682.

Mattingly, H. T., and M. J. Butler. 1994. Laboratory predation on the Trinidadian guppy: implications for the size-selective predation hypothesis and guppy life history evolution. Oikos 69:54-64.

McGuigan, K., C. E. Franklin, C. Moritz, and M. W. Blows. 2003. Adaptation of rainbow fish to lake and stream habitats. Evolution 57:104-118.

McPeek, M. A. 1995. Morphological evolution mediated by behavior in the damselflies of two communities. Evolution 49:749-769.

McPhail, J. D. 1993. Ecology and evolution of sympatric sticklebacks (Gasterosteus): origin of the species pairs. Canadian Journal of Zoology 71:515-523.

. 1994. Speciation and the evolution of reproductive isolation in the sticklebacks (Gasterosteus) of southwestern British Colombia. Pages 399-437 in M. A. Bell 
and S. A. Foster, eds. Evolutionary biology of the threespine stickleback. Oxford University Press, Oxford.

Meacham, C. A. 1993. MorphoSys: an interactive machine vision program for acquisition of morphometric data. Pages 393-402 in R. Fortuner, ed. Advances in computer methods for systematic biology: artificial intelligence, databases, computer vision. Johns Hopkins University Press, Baltimore, Md.

Meffe, G. K., and F. F. Snelson. 1989a. An ecological overview of poeciliid fishes. Pages 13-31 in G. K. Meffe and F. F. Snelson, eds. Ecology and evolution of livebearing fishes (Poeciliidae). Prentice Hall, Englewood Cliffs, N.J. . 1989b. Ecology and evolution of livebearing fishes (Poeciliidae). Prentice Hall, Englewood Cliffs, N.J.

Monaco, T. A., and D. D. Briske. 2001. Contrasting shade avoidance responses in two perennial grasses: a field investigation in simulated sparse and dense canopies. Plant Ecology 156:173-182.

Muller, K. E., and B. L. Peterson. 1984. Practical methods for computing power in testing the multivariate general linear hypothesis. Computational Statistics and Data Analysis 2:143-158.

Olejnik, S., and J. Algina. 2000. Measures of effect size for comparative studies: applications, interpretations, and limitations. Contemporary Educational Psychology 25: 241-286.

O'Steen, S., A. J. Cullum, and A. F. Bennett. 2002. Rapid evolution of escape ability in Trinidadian guppies (Poecilia reticulata). Evolution 56:776-784.

Parenti, L. R., and M. Rauchenberger. 1989. Systematic overview of the poeciliines. Pages 3-12 in G. K. Meffe and F. F. Snelson, eds. Ecology and evolution of livebearing fishes (Poeciliidae). Prentice Hall, Englewood Cliffs, N.J.

Peer, W. A., W. R. Briggs, and J. H. Langenheim. 1999. Shade-avoidance responses in two common coastal redwood forest species, Sequoia sempervirens (Taxodiaceae) and Satureja douglasii (Lamiaceae), occurring in various light quality environments. American Journal of Botany 86:640-645.

Pianka, E. R. 1986. Ecology and natural history of desert lizards. Princeton University Press, Princeton, N.J.

Pigliucci, M., H. Pollard, and M. B. Cruzan. 2003. Comparative studies of evolutionary responses to light environments in Arabidopsis. American Naturalist 161:6882.

Price, T., I. J. Lovette, E. Bermingham, H. L. Gibbs, and A. D. Richman. 2000. The imprint of history on communities of North American and Asian warblers. American Naturalist 156:354-367.

Relyea, R. A. 2001. Morphological and behavioral plasticity of larval anurans in response to different predators. Ecology 82:523-540.
Rencher, A. C. 2002. Methods of multivariate analysis. Wiley, New York.

Reznick, D. N. 1982. The impact of predation on lifehistory evolution in Trinidadian guppies: genetic basis of observed life history patterns. Evolution 36:12361250 .

1989. Life-history evolution in guppies. II. Repeatability of field observations and the effects of season on life histories. Evolution 43:1285-1297.

. 1996. Life history evolution in guppies: a model system for the empirical study of adaptation. Netherlands Journal of Zoology 46:172-190.

Reznick, D. N., and H. A. Bryga. 1996. Life-history evolution in guppies (Poecilia reticulata: Poeciliidae). V. Genetic basis of parallelism in life histories. American Naturalist 147:339-359.

Reznick, D. N., F. H. Shaw, F. H. Rodd, and R. G. Shaw. 1997. Evaluation of the rate of evolution in natural populations of guppies (Poecilia reticulata). Science 275: 1934-1937.

Richardson, J. M. L. 2001. A comparative study of activity levels in larval anurans and response to the presence of different predators. Behavioral Ecology 12:51-58.

Robinson, B. W., and D. S. Wilson. 1994. Character release and displacement in fishes: a neglected literature. American Naturalist 144:596-627.

Rodd, F. H., and D. N. Reznick. 1997. Variation in the demography of guppy populations: the importance of predation and life histories. Ecology 78:405-418.

Rohlf, F. J. 2000. TpsRegr. Version 1.26. Department of Ecology and Evolution, State University of New York, Stony Brook.

Rohlf, F. J., and L. F. Marcus. 1993. A revolution in morphometrics. Trends in Ecology \& Evolution 8:129-132.

Rosen, D. E., and R. M. Bailey. 1963. The poeciliid fishes (Cyprinodontiformes), their structure, zoogeography, and systematics. Bulletin of the American Museum of Natural History 126:1-176.

Ruzzante, D. E., S. J. Walde, V. E. Cussac, P. J. Macchi, M. F. Alonso, and M. Battini. 2003. Resource polymorphism in a Patagonian fish Percichthys trucha (Percichthyidae): phenotypic evidence for interlake pattern variation. Biological Journal of the Linnean Society 78: 497-515.

Schluter, D. 1996a. Adaptive radiation along genetic lines of least resistance. Evolution 50:1766-1774.

- 1996b. Ecological causes of adaptive radiation. American Naturalist 148(suppl.):S40-S64.

- 1996c. Ecological speciation in postglacial fishes. Philosophical Transactions of the Royal Society of London B 351:807-814.

- 2000. The ecology of adaptive radiation. Oxford University Press, Oxford. 
Schluter, D., and J. D. McPhail. 1992. Ecological character displacement and speciation in sticklebacks. American Naturalist 140:85-108.

Seghers, B. H. 1973. Analysis of geographic variation in the antipredator adaptations of the guppy, Poecilia reticulata. Ph.D. thesis, University of British Columbia, Vancouver.

- 1974. Schooling behavior in the guppy (Poecilia reticulata): an evolutionary response to predation. Evolution 28:486-489.

Shaffer, J. P., and M. W. Gillo. 1974. A multivariate extension of the correlation ratio. Educational and Psychological Measurement 34:521-524.

Smith, H., and G. C. Whitelam. 1997. The shade avoidance syndrome: multiple responses mediated by multiple phytochromes. Plant Cell and Environment 20:840-844.

Smith, T. B., and S. Skúlason. 1996. Evolutionary significance of resource polymorphisms in fishes, amphibians, and birds. Annual Review of Ecology and Systematics 27:111-133.

Sohn, J. J. 1977. Consequences of predation and competition upon demography of Gambusia manni (Pisces: Poeciliidae). Copeia 1977:224-227.

Tabachnick, B. G., and L. S. Fidell. 2001. Using multivariate statistics. Allyn \& Bacon, Boston.

Taylor, E. B., and J. D. McPhail. 2000. Historical contingency and ecological determinism interact to prime speciation in sticklebacks, Gasterosteus. Proceedings of the Royal Society of London B 267:2375-2384.

Travisano, M., J. A. Mongold, A. F. Bennett, and R. E. Lenski. 1995. Experimental tests of the roles of adaptation, chance, and history in evolution. Science 267: 87-90.

Van Buskirk, J. 2002. A comparative test of the adaptive plasticity hypothesis: relationships between habitat and phenotype in anuran larvae. American Naturalist 160: 87-102.

Walker, J. A. 1997. Ecological morphology of lacustrine threespine stickleback Gasterosteus aculeatus L. (Gasterosteidae) body shape. Biological Journal of the Linnean Society 61:3-50.

Webb, P. W. 1982. Avoidance responses of fathead minnow to strikes by four teleost predators. Journal of Comparative Physiology 147A:371-378.

- 1984. Body form, locomotion, and foraging in aquatic vertebrates. American Zoologist 24:107-120.

-1986. Effect of body form and response threshold on the vulnerability of four species of teleost prey attacked by largemouth bass (Micropterus salmoides). Canadian Journal of Fisheries and Aquatic Sciences 43: 763-771.

Weihs, D., and P. W. Webb. 1983. Optimization of locomotion. Pages 339-371 in P. W. Webb and D. Weihs, eds. Fish biomechanics. Praeger, New York.

Weinig, C. 2000. Plasticity versus canalization: population differences in the timing of shade-avoidance responses. Evolution 54:441-451.

Wilks, S. S. 1932. Certain generalizations in the analysis of variance. Biometrika 24:471-494.

Williams, E. E. 1983. Ecomorphs, faunas, island size, and diverse end points in island radiations of Anolis. Pages 326-370 in R. B. Huey, E. R. Pianka, and T. W. Schoener, eds. Lizard ecology: studies of a model organism. Harvard University Press, Cambridge, Mass.

Winemiller, K. O. 1991. Ecomorphological diversification in lowland freshwater fish assemblages from five biotic regions. Ecological Monographs 61:343-365.

. 1992. Ecomorphology of freshwater fishes. National Geographic Research and Exploration 8:308-327. Winemiller, K. O., M. Leslie, and R. Roche. 1990. Phenotypic variation in male guppies from natural inland populations: an additional test of Haskins' sexual selection/predation hypothesis. Environmental Biology of Fishes 29:179-191. 